\title{
p-Aminohippurate Transport in the Proximal Straight Tubule: Development and Substrate Stimulation
}

\author{
GEORGE J. SCHWARTZ, DAVID I. GOLDSMITH, ${ }^{(36)}$ AND LEON G. FINE \\ Departments of Pediatrics and Medicine, Albert Einstein College of Medicine, Bronx, New York, USA
}

\section{Summary}

p-Aminohippurate transport by the developing kidney has previously been shown to increase as a function of age and to be enhanced by pretreatment with penicillin. The relative contribution of increases in intrinsic cellular transport capacity and in tubular length was assessed in isolated perfused proximal straight tubules obtained from developing rabbits. The intrinsic capacity for transpurt $\left(10^{-15} \mathrm{M} / \mathrm{min} \cdot \mathrm{mm}\right)$ increased 4.8 -fold $(\mathrm{y}=-315+62.0 \mathrm{x}$, $r=0.69, P<0.005$ ) from 8-19 days of age. Tubular length (microns) also increased $(y=-38.5+52.3 x, r=0.84, P<0.001)$ during the same period. Nine- to 13-day-old animals pretreated with procaine penicillin $(400,000 \mathrm{U})$ divided over 3 days had an intrinsic capacity for transport of $684 \pm 88 \times 10^{-15} \mathrm{M} / \mathrm{min} \cdot \mathrm{mm}$, which was $89 \%$ greater than the $361 \pm 84 \times 10^{-15} \mathrm{M} / \mathrm{min} \cdot \mathrm{mm}$ observed in age-matched, untreated controls $(P<0.02)$. In these groups tubular length was $630 \pm 106 \mu \mathrm{m}$ and $585 \pm 37 \mu \mathrm{m}$, respectively $(P>0.4)$.

\section{Speculation}

Most of the increase in absolute transport (intrinsic capacity $x$ tubular length) seen with age is the result of the increment in the intrinsic transport capacity, while $33 \%$ is a consequence of the rise in the surface area of the transport membrane. Substrate stimulation augments the rate of maturation of the intrinsic transport mechanism without altering the age-related change in the length of the proximal straight tubule.

Uptake of $p$-aminohippurate (PAH) by renal cortical slices and secretion of this substance by the kidney have been shown to rise during development $(7,11,15,21,24,25)$. This may result from increases in intrinsic tubular transport capacity, the ratio of mass of the transporting segments to cortical mass, or both. Pretreatment of young animals with penicillin hastens the increase in uptake or in excretion of $\mathrm{PAH}$, possibly through similar mechanisms $(8,9$, 15). None of the methods thus far used can distinguish between these alternatives. Moreover, they are subject to a number of limitations. For instance, clearance measurements are influenced by the developmental changes in the intrarenal distribution of blood flow $(2,13,22)$, which result in alterations in the delivery of substrate to the secreting segments of differing nephron populations; the slice technique detects only the intracellular accumulation of PAH and as a result gives information which corresponds only tenuously to net transepithelial transport (28). In addition, both methods relate transport to the weight of the tissue studied, yet the proximal tubule, the nephron segment responsible for PAH transport, comprises only a finite portion of the cortical or whole kidney mass. The isolated perfused tubule does not suffer from these limitations. Furthermore, it enables one to identify and measure the individual contribution made by changes in tubular length and intrinsic capacity to the maturation of the renal transport of organic anions.

\section{MATERIALS AND METHODS}

Sixteen suckling New Zealand White rabbits, aged 8-19 days, were studied for the changes in PAH transport with age. The effect of substrate stimulation on the maturation of the transport mechanism was investigated in an additional 8 rabbits, ranging between 10-13 days of age, which were pretreated with sc injections of procaine penicillin at a total dose of $400,000 \mathrm{U}$ over a 2to 3-day period. The results obtained were compared to those observed in age-matched controls.

The animals were killed by a blow to the head, and a 1- to 2mm thick transverse section of the left kidney was transferred to a dish of chilled rabbit serum (Microbiological Associates, Bethesda, MD). As the result of technical difficulties encountered with the extremely thin cortex, we chose to dissect nephrons at random rather than to specifically select either superficial or juxtamedullary nephrons. Dissection of the entire length of a proximal straight tubule (PST), as well as its accurate identification, was assured by removing the terminal convolution of the proximal convoluted tubule and the tapered early descending thin limb. This is clearly demonstrated in Figure 1.

The tubules were transferred to a bathing chamber maintained at $37^{\circ}$ and bubbled with $95 \% \mathrm{O}_{2}-5 \% \mathrm{CO}_{2}$. Tubules were mounted on and perfused through concentric glass pipettes and insulated with Sylgard 184 (Dow Corning, Midland, MI) at both ends as previously described (5). The length of the PST was measured with an ocular micrometer. The holding pipettes and Sylgard seals enclosed less than 10-20 $\mu \mathrm{m}$ (about 5\% of the PST at each end.

The perfusion fluid consisted of $\mathrm{NaCl}, 131 \mathrm{mM} ; \mathrm{NaHCO}_{3}$, $5 \mathrm{mM}$; KCL, $5 \mathrm{mM} ; \mathrm{Na}_{2} \mathrm{HPO}_{4}, 4 \mathrm{mM} ; \mathrm{Na}$ acetate, $5 \mathrm{mM} ; \mathrm{CaCl}_{2}$, $1.8 \mathrm{mM} ; \mathrm{MgSO}_{4}, 1 \mathrm{mM}$; was free of glucose and amino acids, and was titrated to a pH of $6.8(16)$. The osmolality of the bath and that of the perfusate was measured with a Wescor vapor pressure osmometer (Logan, UT). Because of variations in the osmolality of different batches of serum, inequalities between bath and perfusate osmolality were corrected by the addition of small amounts of deionized water to the solution of higher osmolality (final osmolality $288-300 \mathrm{mOsm} / \mathrm{kg} \mathrm{H}_{2} \mathrm{O}$ ). To replace evaporative losses, deionized water was added to the bath throughout the experiment at a rate which maintained conductivity constant (5).

After an initial 20 - to 30 -min equilibration period, three to five timed collections of tubular fluid were obtained in a precalibrated constriction pipette to serve as blanks. Collection rates ranged from 3.4-29 $\mathrm{nl} / \mathrm{min}$. [ $\left.{ }^{3} \mathrm{H}\right] \mathrm{PAH}$ (sp act $127 \mathrm{mCi} / \mathrm{mM}$, New England Nuclear) was then added to the bath to provide a concentration of $2 \times 10^{-4} \mathrm{M}$. After an additional 10- to $15-\mathrm{min}$ equilibration period, three to five additional timed collections were obtained. The samples were placed directly into flasks containing $10 \mathrm{ml}$ Aquasol liquid scintillation fluid (New England Nuclear) and counted on a Packard TriCarb liquid spectrometer. PAH secretion was calculated from the total counts in the collected fluid divided by the product of the specific activity and the collection rate. 

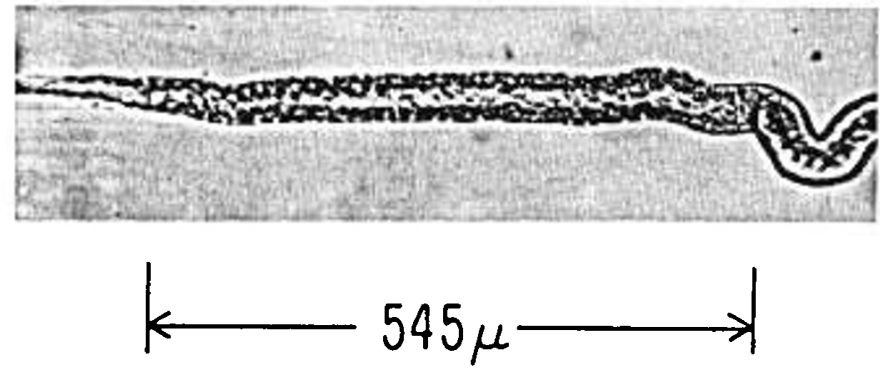

Fig. 1. Photomicrograph of a perfused proximal straight tubule. Note the tapered early descending thin limb of Henle's loop on the left and the terminal convolution of the proximal convoluted tubule on the right. The length of the straight segment is indicated below the figure.

\section{RESULTS}

The length of the PST ranged from 218-981 $\mu \mathrm{m}$ and, as expected, correlated well with age (Fig. 2). The equation describing the least squares regression is y (PST length $\mu \mathrm{m})=-38.48+$ $52.28 \mathrm{x}$ (age in days), $r=0.84, P<0.001$. According to the regression equation a 2.5 -fold increase in PST length would be expected to occur within the age range studied. Close inspection of the data points reveals that two PSTs in 8-day-old animals were substantially shorter than the third and suggests that a curvilinear relationship may obtain during the early stages of development.

The intrinsic capacity (transport of PAH per mm tubular length) increased significantly with age (Fig. 3). The large degree of variability usually found in isolated perfused tubules is evident. The design of the study, however, precluded comparing each tubular segment to itself and thus limiting the scatter. Nevertheless, a significant regression was obtained by least square analysis $\mathrm{y}\left(10^{-15} \mathrm{~mol} / \mathrm{min} \cdot \mathrm{mm}\right)=-314.61+62.04 \mathrm{x}, r=0.69, P<0.005$. For the age range studied a 4.8 -fold increase in intrinsic capacity can be calculated from the regression. Consequently, absolute PAH secretion, the product of intrinsic capacity and tubular length, had to increase since each of its components was found to rise with age. The effect of the increase in intrinsic capacity on absolute transport was nearly twice that of the rise in PST length.

There was no correlation between collection rate on the one hand and age, tubular length, or intrinsic transport capacity on the other.

Table I presents the data obtained from the 16 animals 9-13 days of age, half of which were pretreated with procaine penicillin. The mean age of the pretreated group was $11.3 \pm 0.4$ days, whereas the control group was $11.1 \pm 0.4$. The difference is due to only one pair where the control animal was studied 1 day later than the experimental animal. There was no significant difference between experimental and control animals in regard to collection rate $(12.1 \pm 1.6 \mathrm{nl} / \mathrm{min}$ and $15.3 \pm 3.1 \mathrm{nl} / \mathrm{min}$, respectively $), P>$ 0.3 . Tubular length in the penicillin-pretreated group $(630 \pm 106$ $\mu \mathrm{m})$ was more variable $(\mathrm{F}=8.18, P<0.01)$ than in the control group $(585 \pm 37 \mu \mathrm{m})$. However, there was no significant difference between the mean value observed when tested by either parametric ( $t$-test adapted for unequal variance) or nonparametric statistics (Mann-Whitney U-test), $P>0.4$ (3).

The intrinsic transport capacity was $684 \pm 88 \times 10^{-15}$ $\mathrm{mol} / \mathrm{min} / \mathrm{mm}$ after penicillin pretreatment whereas it was only $361 \pm 84$ in the control group. This is equivalent to an $89 \%$ increase in intrinsic transport capacity $(P<0.02)$.

\section{DISCUSSION}

PAH uptake by renal cortical slices $(21,24)$ and renal extraction in whole animal studies $(11,21,25)$ have previously been shown to increase as a function of age and to be stimulated by pretreatment with penicillin $(7-9,15)$. Mechanisms suggested to account for the observed developmental changes and response to substrate stimulation include increases in intrinsic transport capacity, tubular mass, and availability of substrate. Another mechanism by

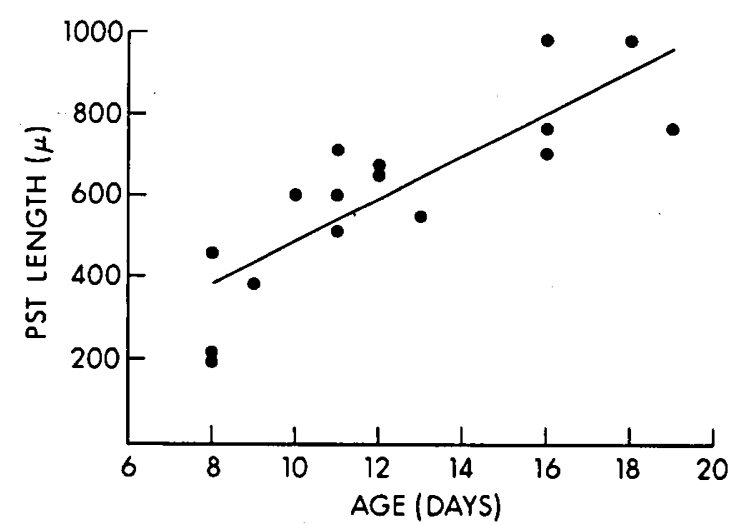

Fig. 2. Proximal straight tubule length (y) as a function of age (x). $y=$ $-38.5+52.3 \mathrm{x}, r=0.84, P<0.001$.

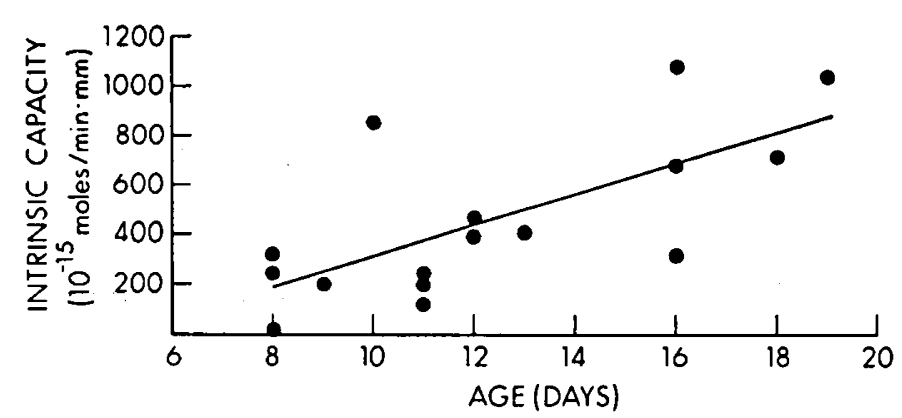

Fig. 3. Intrinsic capacity for $\mathrm{PAH}$ transport $(\mathrm{y})$ as a function of age (x). $\mathrm{y}=-315+62.0 \mathrm{x}, r=0.69, P<0.005$.

Table 1. Data from 16 animals

\begin{tabular}{|c|c|c|c|c|}
\hline & $\begin{array}{l}\text { Age, } \\
\text { days }\end{array}$ & $\begin{array}{c}\text { Intrinsic } \\
\text { capacity, } \\
10^{-15} \\
\mathrm{~mol} / \\
\mathrm{min} \cdot \mathrm{mm}\end{array}$ & $\begin{array}{c}\text { PST } \\
\text { length, } \\
\mu \mathrm{m}\end{array}$ & $\begin{array}{l}\text { Collection } \\
\text { rate, } \\
\text { nl/min }\end{array}$ \\
\hline \multicolumn{5}{|c|}{ Control $(n=8)$} \\
\hline Mean & 11.1 & 361 & 585 & 15.3 \\
\hline SE & 0.4 & 84 & 37 & 3.1 \\
\hline \multicolumn{5}{|c|}{ Penicillin $(n=8)$} \\
\hline Mean & 11.3 & 684 & 630 & 12.1 \\
\hline SE & 0.4 & 88 & 102 & 1.6 \\
\hline$P$ & $>0.8$ & $<0.02$ & $>0.6$ & $>0.3$ \\
\hline
\end{tabular}

which these changes might occur is genesis of nephrons with a greater transport capacity and/or length.

It is evident from these studies that both the intrinsic capacity and tubular length increase as a function of age during the period of development, and the increase in transport cannot be related to an increased substrate availability since the concentration of PAH $\left(2 \times 10^{-4} \mathrm{M}\right)$ in the bath was constant. Unlike the studies which utilize cortical slices, these experiments do not suffer from problems involving the known changes in the ratios of extracellular/intracellular water content (6) or proximal tubular mass/cortical mass (4) which occur during development. Thus, these observations must be due to either a maturational phenomenon or the neogenesis of nephrons with a longer PST and a greater intrinsic transport capacity.

It has been clearly established that renal growth $(10,12,19,20$, $23)$ and functional maturation $(2,13,14,17,22)$ proceed centrifugally. This is associated with the development of a progressively more superficial population of nephrons, and presents a potential 
obstacle to the investigation of maturation at the single nephron level. The problem derives from the fact that newly formed nephrons with specific morphologic and functional characteristics are added to the already existent population and might be randomly chosen for study. Moreover, the stage of maturation is probably variable even among the older nephrons. The problem is further magnified by nephron heterogeneity. In particular, it has been suggested that PAH transport may be greater in the superficial straight proximal tubule when compared to those occupying the deeper cortex (29). This difference may be related to the location and transport rates of specific cell types observed in the deep and superficial segments (30). It is therefore conceivable that the apparent change in measured intrinsic capacity which we observed could merely be a reflection of the differences in cell type or the site of origin of the proximal straight tubules studied, rather than a result of a maturational process which occurs on the level of a single nephron.

Several considerations lead us to reject the hypothesis that the results of this study might be explained solely on the basis of the selection problem which derives from nephronogenesis. First, the mean transport rate which we observed in 8-day-old animals (190 $\times 10^{-15} \mathrm{M} / \mathrm{min} \cdot \mathrm{mm}$ ) is similar to that found by Woodhall in the adult rabbit juxtamedullary PST $\left(253 \times 10^{-15} \mathrm{M} / \mathrm{min} \cdot \mathrm{mm}\right)$, despite the fact that the concentration of PAH in the bath was 5fold greater in our studies. This suggests that even if the nephrons selected were from the juxtamedullary region, their transport rate is less than that observed in adult animals. Second, the studies of the development of single nephron function in animals with completed nephronogenesis at birth, such as the guinea pig, have conclusively shown that development of the single nephron glomerular filtration rate of the superficial nephrons lags behind that of the deep nephrons (27). Similarly, a lag in the development of PAH uptake by outer cortical slices as compared to slices from the deep cortex has been reported by Rennick et al. (24). It is therefore likely that the study of newly formed superficial nephrons would result in lower values of intrinsic capacity rather than lead to erroneously high values. Third, PAH uptake by cortical slices has been shown to increase after nephronogenesis has been completed (7), which is inconsistent with the hypothesis that the increase in PAH transport derives solely from the neogenesis of "high transport capacity" nephrons. Finally, an approximation can be made to roughly assess the impact of nephronogenesis on the development of the intrinsic capacity. Several assumptions are required: 1) in contrast to the 200,000 nephrons present in the adult rabbit (18), only 100,000 are estimated to be present in the newborn of this species. This value is a gross approximation and is based on reports of nephronogenesis in the $\operatorname{dog}(22)$ and rat $(1) ; 2)$ approximately $25 \%$ of the adult nephron population is considered to be "juxtamedullary"; 3) all of the nephrons formed after birth are superficial. Thus, in the adult rabbit, 50,000 nephrons are found in the deep cortex and by definition the same number is present in the newborn rabbit, leaving 50,000 superficial nephrons. The probability of randomly selecting a superficial nephron is therefore $50 \%$, whereas in the adult it is $75 \%$. Assuming that all the nephrons, including the newly formed superficial ones, function at the mature secretion rates of Woodhall et al. (29), the selection difference could account for a rise in transport capacity from $795-1068.5 \times 10^{-15} \mathrm{~mol} / \mathrm{min} \cdot \mathrm{mm}$, an increment of $34 \%$. In contrast, our data demonstrate more than a 4-fold increase in intrinsic transport capacity. We therefore conclude that even if the superficial nephrons, shortly after their formation, were to function at rates equivalent to those observed in PST segments of the mature animal (an unlikely event), random selection of these nephrons cannot account for the pattern observed by us. However, as already mentioned, the maturation of the intrinsic capacity is only one of the factors responsible involved in this process. The increase in tubular length plays a lesser, but significant, role.

The studies on the effect of penicillin pretreatment show that the maturation of PAH transport mechanism can be stimulated, as originally shown in cortical slices by Hirsch and Hook (8), and subsequently confirmed by clearance studies in animals (15) and in a human subject (26). Our results demonstrate that this phenomenon is due solely to a rise in intrinsic transport capacity with no concomitant increase in tubular length. The finding appears to be inconsistent with the observation that penicillin pretreatment resulted in an increase in kidney weight $(8,15)$, the ratio of kidney to body weight, and the protein content of the kidney (9). However, since volume, hence weight, varies roughly with the cube of the whole kidney thickness, minimal changes in this dimension or renal water content, unrelated to changes in the length of the straight proximal tubule, may have profound effects on kidney weight. Similarly, small changes in the degree of basolateral membrane infoldings may result in large increases in surface area available for PAH transport and kidney protein content with no apparent alteration of tubular length. Our data do not permit a kinetic analysis to determine whether the substrate stimulated increase in PAH secretion resulted from increases in the number and/or affinity of transport sites, nor do they allow us to determine whether the membrane surface area available for transport was affected.

In conclusion, we have shown that the increase in PAH secretion which occurs during maturation is explained by a rise in the intrinsic capacity for transepithelial transport and by elongation of the tubule. The former mechanism is responsible for the bulk of the rise in PAH secretion by the PST during this particular age span and its rate of development is enhanced by pretreatment with penicillin.

\section{REFERENCES AND NOTES}

1. Arataki, M.: On the postnatal growth of the kidney with special reference to the number and size of the glomeruli (albino rat). Amer. J. Anat., 36: 399, (1926).

2. Aschinberg, L. C., Goldsmith, D. I., Olbing, H., Spitzer, A., Edelmann, C. M., Jr., and Blaufox, M. D.: Neonatal changes in renal blood flow distribution in puppies. Amer. J. Physiol., 228: 1453 (1973).

3. Dixon, W. J., and Massey, F. J.: Introduction to Statistical Analysis, Ed. 3, pp. 119, 334 (McGraw-Hill Book Co., New York, 1969).

4. Fetterman, G. H., Shuplock, N. A., Phillip, F. J., and Gregg, H. S.: The growth and maturation of human glomeruli and proximal convolutions from term to adulthood. Studies by microdissection. Pediatrics, 35: 601 (1965).

5. Fine, L. G., Bourgoignie, J. J., Hwang, K. H., and Bricker, N. S.: On the influence of the natriuretic factor from patients with chronic uremia on the bioelectric properties and sodium transport of the isolated mammalian collecting tubule. J. Clin. Invest., 58: 590 (1976).

6. Friis-Hansen, B.: Body water compartments in children: Changes during growth and related changes in body composition. Pediatrics, 28: 169 (1961).

7. Hirsch, G. H., Cowan, D. F., and Hook, J. B.: Histological changes in normal and drug-induced development of renal PAH transport. Proc. Soc. Exp. Biol. Med., 137: 116 (1971).

8. Hirsch, G. H., and Hook, J. B.: Maturation of renal organic acid transport: Substrate stimulation by penicillin. Science, 165: 909 (1969)

9. Hirsch, G. H., and Hook, J. B.: Stimulation of renal organic acid transport and protein synthesis by penicillin. J. Pharmacol. Exp. Ther., 174: 152 (1970).

10. Horster, M., Kemler, B. J., and Valtin, H.: Intracortical distribution of number and volume of glomeruli during postnatal maturation in the dog. J. Clin. Invest., 50: 796 (1971)

11. Horster, M., and Lewy, J. E.: Filtration fraction and extraction of PAH during neonatal period in the rat. Amer. J. Physiol., 219: 1061 (1970).

12. Huber, G. C.: The morphology and structure of the mammalian rena' tubule. Harvey Lect., 5: 100 (1909-1910).

13. Jose, P. A., Logan, A. G., Stotkoff, L. M., Lilienfield, L. S., Calcagno, P. L., and Eisner, G. M.: Intrarenal blood flow distribution in canine puppies. Pediat. Res., 5: 335 (1971).

14. Jose, P. A., Zimmet, S., Flamenbaum, W., Eisener, G., and Calcagno, P.: Distribution of single nephron filtration in the newborn dog [Abstr.]. Annual Meeting American Society of Nephrologists, Washington, D.C., p. 85, 1975.

15. Kaplan, M. R., Rucker, B., and Lewy, J. E.: In vivo analysis on PAH transport in the maturing rabbit kidney [Abstr.]. Pediat. Res., 10: 440 (1976).

16. Kawamura, S., Imai, M., Seldin, D. W., and Kokko, J. P.: Characteristics of salt and water transport in superficial and juxtamedullary straight segments of proximal tubules. J. Clin. Invest., 55: 1269 (1975).

17. Kleinman, L. I., and Reuter, J. H.: Maturation of glomerular blood flow distribution in the newborn dog. J. Physiol., 228: 91 (1973).

18. Kunkel, P. A., Jr.: The number and size of the glomeruli in the kidney of several mammals. Bull. Johns Hopkins Hosp., 47: 285 (1930).

19. Ljunquist, A.: Fetal and postnatal development of the intrarenal arterial pattern in man: A microangiographic and histologic study. Acta Pediat. Scand., 52: 443 (1963).

20. MacDonald, M. D., and Emery, J. L.: The late intrauterine and postnatal development of human renal glomeruli. J. Anat., 93: 331 (1959). 
21. New, M., McNamara, H., and Kretchmer, N.: Accumulation of para-aminohippurate by slices of kidney from rabbits of various ages. Proc. Soc. Exp. Biol. Med., 102: 558 (1959).

22. Olbing, H., Blaufox, M. D., Aschinberg, L. C., Silkalns, G. I., Bernstein, J. Spitzer, A., and Edelmann, C. M., Jr.: Postnatal changes in renal glomerular blood flow distribution in puppies. J. Clin. Invest., 52: 2885 (1973).

23. Osathanondh, V., and Potter, E. L.: Development of human kidney as shown by microdissection. III. Formation and interrelationship of collecting tubules and nephrons. Arch. Pathol., 76: 290 (1963).

24. Rennick, B., Hamilton, B., and Evans, R.: Development of renal tubular transport of TEA and PAH in the puppy and piglet. Amer. J. Physiol., 201: 743 (1961)

25. Rubin, M. I., Bruck, E., and Rapoport, M.: Maturation of renal function in childhood: Clearance studies. J. Clin. Invest., 28: 1144 (1949).

26. Schwartz, G. J., Hegyi, T. H., and Spitzer, A.: Subtherapeutic dicloxacillin levels in a neonate: Possible mechanisms. J. Pediat., 89: 310 (1976).

27. Spitzer, A., and Brandis, M.: Functional and morphologic maturation of the superficial nephrons. J. Clin. Invest., 53: 279 (1974).

28. Weiner, I. M.: Transport of weak acids and bases. In: J. Orloff and R. W. Berliner: Handbook of Physiology, Section 8: Renal Physiology, pp. 521-554 (Williams \& Wilkins, Baltimore, 1973).

29. Woodhall, P. B., Tisher, C. C., Simonton, C. A., and Robinson, R. R.: Relation- ship between $p$-aminohippurate (PAH) secretion and cellular morphology in superficial (SF) and juxtamedullary (JM) straight segments of proximal tubules (PT) [Abstr.]. Clin. Res., 24: 40A (1976).

30. Woodhall, P. B., Tisher, C. C., Simonton, C. A., and Robinson, R. R.: Relationship between $p$-aminohippurate secretion and cellular morphology in superficial and juxtamedullary proximal tubules [Abstr.]. Clin. Res., 24: 417A (1976),

31. Dr. Fine was supported by USPHS Program Project no. AM-16281

32. Dr. Fine's present address is Division of Nephrology, University of Miami School of Medicine, PO Box 520875, Biscayne Annex, Miami, FL 33152.

33. Dr. Schwartz was supported by Research Fellowship Award AM 00129 of the NIH.

34. Dr. Schwartz' present address is Laboratory of Kidney and Electrolyte Metabolism, NIH, Bethesda, MD 20014.

35. Dr. Goldsmith was supported in part by the NIH Grant AM 14877 and the Health Research Council Grant 282.

36. Requests for reprints should be addressed to: Dr. David I. Goldsmith, Rose F. Kennedy Center, Room 721, 1410 Pelham Parkway South, Bronx, NY 10461 (USA).

37. Received for publication August 22, 1977

38. Accepted for publication October 10, 1977.

Copyright $(\mathcal{C} 1978$ International Pediatric Research Foundation, Inc. $0031-3998 / 78 / 1207-0793 \$ 02.00 / 0$ 